



\title{
Visiones panorámicas sobre la Nueva Sociologia Económica. Entrevista al sociólogo Alejandro Portes
}

\author{
Jefferson Jaramillo ${ }^{1}$ \\ Pontificia Universidad Javeriana, \\ Bogotá, Colombia \\ jefferson.jaramillo@javeriana.edu.co \\ Didier Restrepo ${ }^{2}$ \\ Pontificia Universidad Javeriana, \\ Bogotá, Colombia \\ didierrestrepo@javeriana.edu.co
}

El profesor Alejandro Portes es un sociólogo de origen cubano. Recibió su Ph.D. en Sociología de la Universidad de Wisconsin-Madison en 1970. Es profesor del departamento de Sociología de la Universidad de Princeton y miembro de la Academia Nacional de Ciencias. Además, se desempeñó como director del Centro para las Migraciones y el Desarrollo. Sus recientes investigaciones están orientadas hacia la comprensión del problema de inmigración a los Estados Unidos, así como de los factores que impactan el destino de los inmigrantes y sus hijos; es un especialista en estudios urbanos, marginalidad social y migraciones transnacionales. En la actualidad, Portes es uno de los sociólogos de referencia en habla hispana y uno de los más influyentes en el análisis del desarrollo comparado de América Latina y de la sociología económica de comienzos del siglo XXI.

\footnotetext{
Doctor en Ciencias Sociales, FLACSO (México). Profesor Asociado, Departamento de Sociología, Pontificia Universidad Javeriana (Bogotá, Colombia).

2 Doctor en Ciencias Sociales y Humanas, Pontificia Universidad Javeriana (Colombia). Profesor, Departamento de Economía (curso: "Grupos Sociales, Poder y Mercados"), del Doctorado en Ciencias Sociales y Humanas y del Departamento de Sociología (cursos: "Política Social", "Desarrollo y Gerencia Social"), Pontificia Universidad Javeriana (Bogotá, Colombia).
} 
En el marco de una visita realizada el 18 de agosto de 2011, a la Pontificia Universidad Javeriana en Bogotá, Portes intercambió ideas con estudiantes del Doctorado en Ciencias Sociales y con profesores del departamento de Sociología, acerca de la naturaleza y los desafios de la nueva sociología económica. La conversación que aquí sintetizamos y editamos, reúne los principales momentos e impresiones de este encuentro.

Jefferson Jaramillo (J.J.): profesor Portes, usted estaria dentro de lo que algunos denominan la nueva sociologia económica, la que busca darle un papel protagónico a las estructuras y a las instituciones en el desarrollo de las sociedades, cuestionando el modelo clásico del "rational choice". ¿Cómo percibe en la actualidad este campo de la nueva sociología económica?

Alejandro Portes (A.P.): la nueva sociología económica surgió como una especie de respuesta a la "cruzada intelectual" de ciertos economistas neoclásicos que buscaban extender la aplicabilidad de los modelos y teorías de la acción hacia otros terrenos inexplorados antes por ellos, como la familia, el crimen, la migración, el capital social, el mercado de trabajo y las redes sociales. A mi juicio, fue el economista Gary Becker, de la Universidad de Chicago, quien inició esta cruzada, planteando que el modelo de acción racional que subyacía a la economía neoclásica actual no solo era útil para la teoría económica, sino también para todo tipo de esferas de conocimiento. Una minoría de prominentes sociólogos, entre ellos James Coleman, quedarian seducidos por estos modelos de acción racional, pero también algunos politólogos a través de la "public choice", lo cual indicaba el nivel de penetración de la economía dentro de estos dos campos de conocimiento.

Sin embargo, en la sociología sucedió algo que no ocurrió en la ciencia política: se dio una reacción elocuente contra la idea del modelo de acción racional individual, como el supuesto básico que debía adoptar la ciencia social en general. A contracorriente de este mandato, los sociólogos de diversas estirpes encontrarán en autores como Durkheim un supuesto más sólido de la disciplina, y es que la 
sociedad a través del proceso de socialización ejerce coacción sobre la acción individual, no siendo la sociedad una simple suma de individuos. Esta idea base de la disciplina es contraria a la idea de una sociedad de individuos que, de manera racional e independiente de influencias sociales, decide todo en términos de cálculo. El sociólogo que inició esta especie de contraofensiva frente a la cruzada de la visión económica ortodoxa fue Granovetter en su artículo de $1985^{3}$. En este artículo, Granovetter se refiere al problema del encaje social de la acción racional, cuestionando la aplicación del modelo de acción racional a los ámbitos de lo social, como son la familia, el crimen y la migración. Además, plantea que los propios fenómenos económicos son sociales y están afectados por el problema de la incrustación social, dado el hecho de que la interacción entre los actores económicos fluye desde los niveles más profundos, es decir, desde lo simbólico de la vida social. Yo creo que el vigor de la sociología económica actual, tanto en Norteamérica como en Francia e Inglaterra, tiene mucho que ver con el cuestionamiento directo al modelo de mercados autorregulados. Sin embargo, debo decir que todavía no se ha registrado una especie de contra-modelo propiamente sociológico frente a la economía, que haga un contrapeso fuerte. La sociología económica en la actualidad consiste en críticas a las conclusiones fundamentales, críticas a las limitaciones de un modelo de mercado autorregulado. El tema es que no podemos quedarnos simplemente en la crítica, sino que debemos proveer una mejor teoría sobre los mecanismos de funcionamiento de la realidad social.

\section{Didier Restrepo (D.R.): se ha investigado desde la sociologia eco- nómica sobre redes sociales, sobre capital, sobre mercado de tra- bajo, sobre la desigualdad en el mercado laboral. Desde su óptica, ¿qué campos no se han cubierto?}

A.P.: aunque se ha estudiado el mercado, faltan análisis en profundidad sobre sus mecanismos sociales de funcionamiento. Es decir, se hacen estudios de caso sobre un mercado aquí, una empresa luego, pero no se hacen de forma sistemática. En mi criterio, la clave está en volver sobre

\footnotetext{
3 Se refiere al artículo: "Economic Action and Social Structure: The Problem of Embeddedness".
} 
el concepto de institución y al análisis de la acción económica, desde la acción institucional, lo que anteriormente se llamaba el encaje social. Es decir, examinar cómo la interacción social modifica a la institución y cómo esta transforma las acciones sociales. Este análisis de lo que son las instituciones puede llevarnos a explicar sus éxitos y fracasos; sus logros en el desarrollo nacional, así como el fracaso de los mercados y los instrumentos financieros. Los fenómenos económicos son también sociales, el "encaje" de la economía en el marco de la interacción social es importante, ya que los actores económicos a través de sus acciones repetidas generan conductas sociales.

\section{J.J.: ¿Cómo examina usted el desarrollo de la sociología económi- ca desde América Latina?}

A.P.: en América Latina la sociología económica sigue en desarrollo, aunque muy en relación con ciertos "centros intelectuales" donde esta temática es fundamental, especialmente Francia. Creo que esta tiene que jugar un gran papel, porque permite salirse de la sensación de orfandad de legitimidad de la sociología como interlocutora de gobiernos y otros sectores del poder dentro de nuestras sociedades. Además, como productora de sugerencias que sean tomadas en serio en términos de política social. La sociología desde los años sesenta sufrió de una "excesiva politización", quizá por la necesidad de denuncia que hubo frente a la enorme desigualdad existente en el continente, quizá por la necesidad urgente de transformaciones revolucionarias. Sin embargo, eso mismo llevó a las élites de poder a marginar la disciplina y a otorgarles más legitimidad a las disciplinas hermanas, en concreto a la economía. Mi percepción es que la sociología debe recuperar su lugar como interlocutora de los mismos fenómenos que son de interés para la economía como disciplina. La sociología provee discusiones serias sobre los marcos institucionales, explicaciones sobre cómo funcionan ciertas politicas sociales. En ese sentido, creo que el hecho de que en América Latina los intelectuales dialoguen a nivel público entre ellos y con otros colegas de otras latitudes es una oportunidad. En Estados Unidos, muchas veces es limitado el poder incidir en el futuro, sobre todo en políticas que impulsen el desarrollo económico, 
social y politico. Para los latinoamericanos, es una ventana de oportunidad producir caminos renovados para la sociología del desarrollo.

\section{D.R.: en un texto del 2004, publicado por FLACSO - Costa Rica, donde participaron algunos profesores de Economia, se resumen tres postulados teóricos básicos de la sociología económica: la acción económica es una forma de acción social, la acción eco- nómica está imbricada en estructuras sociales, las instituciones sociales son construcciones sociales. ¿Qué les agregaria usted a esos postulados?}

A.P.: agregaría dos más, pero más bien como metasupuestos o metapostulados, los cuales constituyen los lentes a través de los cuales nos aproximamos al mundo, y que desarrollo en mi último libro sobre sociología económica ${ }^{4}$. El primero está relacionado con las consecuencias inesperadas de la acción racional y tiene una amplia tradición que transita desde Simmel hasta Merton, permitiendo entender los giros inesperados de la acción social, en contravía del viejo modelo: fines iniciales - medios racionales - logros lineales, modelo que no toma en cuenta otros factores. ¿Cuáles son esos factores? El hecho de que tanto la interacción social como las estructuras de poder existentes modifican las acciones, y que, por tanto, la sociología no puede ceder frente a afirmaciones lineales. Tal politica lleva a que deseemos producir estos resultados y a que la proyectemos para llegar a ellos, cosa que ocurre muchas veces en el sentido no dialéctico del pensamiento económico moderno. La idea de consecuencias inesperadas es que la acción económica como dialéctica, o sea, sujeta a contradicciones y pudiendo llevar a los fines esperados en alguna ocasión, no siempre opera de esa manera. Incluso he desarrollado una tipología en otro ensayo que está incluido en este último libro sobre las alternativas o consecuencias inesperadas de la acción racional.

El segundo elemento que importa es el poder y su cristalización en las clases sociales. $\mathrm{Al}$ respecto, ha habido algunas criticas en esta dirección al planteamiento de Mark Granovetter, porque no tiene en

\footnotetext{
4 Hace alusión al libro Sociología económica: una investigación sistemática, publicado en español en 2013.
} 
cuenta los diferenciales de poder al interior de las clases sociales, al referirse a la teoría del encaje social de la acción económica que ocurre entre actores que parecerían tener más o menos el mismo nivel de poder. No obstante, lo que ocurre en realidad es que las acciones económicas y sus resultados tienen mucho que ver con los recursos materiales y no materiales que controlan diversos agentes sociales en la estructura social. Es decir, yo situaría el poder como metasupuesto, un postulado importante, que, entre otras cosas, permite incluir dentro de la nueva sociología económica los hallazgos más importantes de la economía política clásica, que reconoce los diferenciales de poder y sus resultados.

\section{J.J.: en esa medida una pregunta que uno podria hacerse es, ¿cómo profundizar más en los temas culturales desde la sociolo- gía económica?}

A.P.: a mi modo de ver los desarrollos más importantes en ese sentido se asocian con los nombres de Viviana Zelizer y Paul DiMaggio. Zelizer es una socióloga de Princeton, quien en su libro El significado social del dinero ${ }^{5}$ analiza cómo esta entidad que pareciera ser absolutamente económica o anónima tiene diversos usos sociales dentro de las empresas o la familia. Además, según ella, existen diversos tipos de dinero para determinadas cosas, es decir, no solo existe el papel moneda, sino que hay otras formas de crear y utilizar socialmente el dinero. Paul DiMaggio, por su parte, analiza cómo la cultura a través de las normas existentes afecta el comportamiento económico de actores tanto corporativos como individuales, enfatizando que sus acciones no corresponden de manera mecánica a la simple maximización de los beneficios, como tampoco a la minimización de los costos.

Un estudio de caso sirve para ilustrar esto último: el análisis del comportamiento real de ejecutivos de una gran multinacional en New York. En este estudio, se muestra cómo una de las preocupaciones dominantes de los ejecutivos de la empresa no era la maximización de las ganancias de los accionistas, sino más bien mantener su honor

5 Traducido y publicado por el Fondo de Cultura Económica en 2011. 
y prestigio con respecto a sus colegas y a los de otras corporaciones. En el estudio se señala cómo, para mantener el prestigio y el honor, dedicaban largas horas a discutir sobre el valor que revisten ciertas actividades técnicas que justifican su estatus. Más que la creación de bienes de la propia empresa, una de sus principales preocupaciones se asociaba al honor social, al prestigio. Este es simplemente uno de tantos ejemplos en los que la cultura da forma a la acción económica. Ejemplos como estos hay por miles, sin embargo, la pregunta para la sociología económica es: ¿cómo sistematizar estos hallazgos en procura de avanzar hacia una formalización teórica sobre los impactos de la cultura o del poder en la estructura social y en la acción económica?

\section{D.R.: finalmente, en el caso colombiano la sociología económica no ha tenido desarrollos como en México y Chile. ¿A qué se debe esto? ¿Qué recomendaría usted para que la sociología económica pueda ganar más protagonismo e impacto al interior de la disci- plina sociológica?}

A.P.: yo creo que en la actualidad hay muchos economistas desencantados con los planteamientos del modelo ortodoxo y con sus resultados; economistas institucionales que han salido de escuelas de Norteamérica y Europa, etc., y que se vuelven aliados naturales en el hecho de encontrar que se necesita algo más para comprender cómo se comportan los actores económicos y cómo funcionan o no las políticas económicas. Sin embargo, lo que no tienen es la formación sociológica, en términos de un marco conceptual que les permita tener un lente alternativo en esa cuestión. Yo lo que recomendaría es la promoción de este nuevo enfoque dentro de las carreras de sociología y dentro de los centros interdisciplinarios, para que sea posible mantener un diálogo continuo entre economía y sociología alrededor de las politicas de desarrollo. La sociología debe recuperar el espacio que perdió, aportando análisis que amplien la mirada sobre la apertura y flexibilización de los mercados, ámbitos en los que ha existido hasta ahora una hegemonía de la economía ortodoxa, que a través de sus politicas ha tenido consecuencias funestas para la sociedad. 
Respecto a las diferencias de desarrollo de la sociología económica entre países, considero que probablemente México - porque está más cerca a Estados Unidos-, ha recibido más influjo de los aportes de este cambio. Sin embargo, el problema de la sociología económica en Estados Unidos es que corre el riesgo de perderse en estudios puntuales de caso, sin lograr hasta el momento una suficiente formalización teórica que logre incorporar las consecuencias inesperadas del comportamiento de los agentes, así como los diferenciales de poder. Una posible vía para enfrentar esta formalización sería tomar en consideración análisis históricos del desarrollo y sus efectos a través de las políticas implementadas. Quizá esto nos abra nuevas posibilidades para la disciplina y para garantizar que las políticas económicas y sociales tengan más éxito que en el pasado.

J.J.: Muchas gracias, profesor Portes. Hasta una nueva oportunidad. 


\section{Referencias}

Granovetter, M. (1985). Economic Action and Social Structure: The Problem of Embeddedness. American Journal of Sociology, 91(3), 481-510.

Portes, A. (2013). Sociología económica: una investigación sistemática. Madrid: Centro de Investigaciones Sociológicas.

Zelizer, V. (2011). El significado social del dinero. Buenos Aires: Fondo de Cultura Económica.

\section{Cómo citar este artículo}

Jaramillo, J. y Restrepo, D. (2017). Visiones panorámicas sobre la Nueva Sociología Económica. Entrevista al sociólogo Alejandro Portes. Universitas Humanística, 83, 391-399. http://dx.doi.org/10.11144/Javeriana.uh83.vpns 